\title{
Primary care in Hong Kong: a lesson about competition
}

GPs in Britain viewing the growth of competition often use US primary care as the case study of the consequences of letting the market shape medical practice. There is another example from a place that was, until relatively recently, under British jurisdiction; Hong Kong.

Primary care in Hong Kong is provided from at least six distinct sources:

1. The government-run hospitals provide general outpatient clinics (GOPCs) and accident and emergency (A\&E) departments, to which patients can selfrefer. Patients are charged for consultations, but the charge includes medication costs.

2. Private GPs are numerous. They provide the majority of primary care consultations, tend to work alone, and charge fees that also include medication costs. Although most patients still pay cash, insurance policies are becoming more common, and about $40 \%$ of working age citizens have some insurance/employer subsidy for medical care.

3. Private group practices, which in some ways are like health maintenance organisations (HMOs), have developed; some are run by international companies like BUPA and Blue Cross, and others by local organisations.

4. The third sector, non-government organisations among which the churches are major stakeholders, is the main provider of social care. It is very much locality-based, and it's connections with GPs and specialists gives it some features of a communityoriented primary care movement. It too has to work within the financing system, so users are charged.

5. Traditional Chinese Medicine (TCM) practitioners are a strong competitor in the primary care economy.

6. Academic group practices attached to universities also provide primary care services (within government general outpatient departments), but also operate within the funding system and so charge patients. They are probably too few and too small to make any independent impact on the overall system.

The main competition is between private GPs and the government hospitals. The GOPCs and A\&E departments charge lower fees and give more medicine (longer prescriptions) than GPs, and so attract patients. However, they are then overloaded and unable to meet demand, so limit it by, for example, capping appointment numbers. The overflow demand tends to go to private GPs, who are more accessible. The financial situation of GPs may become precarious, and practitioners may opt to give up private practice and become salaried employees of HMOs.

The GOPCs charge HK\$44 (about £3) per encounter, which includes consultation, medication, and any lab tests needed. A\&E departments charge HK\$100 (less than £7) per visit, which also includes all the necessary treatment/investigations but no follow-up.

There are no 'guidelines/standards' for fee-charging in the private sector. The GP in private practice has to cover the costs of staff, rent, purchase of drugs, supplies, equipment, and other overheads. Solo GPs lack economy of scale for drugs and medical supplies, which greatly hinders their provision of long-term chronic disease care (particularly drugs) as the resulting costs are transferred to the patient, who quickly decides that it's much cheaper to go to the GOPC for the same drugs. In fact, many older patients who have hypertension or diabetes refer to the GOPC as the place for 'getting medicine' (rather than to 'visit the doctor' or for 'consultation'). Many patients use both private GP and government OPC, depending on the type of problem. For example, most would go to a private GP near home for treatment of upper respiratory tract infections because the service is quick and the GP is likely to provide medicines for a reasonable fee of about $\$ 150$ (about £10) which is affordable to most; but for problems requiring long-term treatment, the GOPC and specialist hospital clinics are preferred, both for cost reasons and because of the accurate perception that the hospitals have the medical equipment that the GP does not have.

The quasi-HMO primary care providers are essentially group practices with salaried doctors, but most are not true HMOs in the US sense of the term. These group practices are still mostly 'fee for service', charging each patient per visit and per item, rather than taking an annual subscription that is all-inclusive. They experience economies of scale in terms of procuring and providing medication, and try to integrate health promotion programmes into general primary care services. Many of the younger doctors are joining the quasi-HMOs straight after their hospital training as the financial rewards can be significant. (Most quasi-HMOs offer basic salary and a bonus system that rewards according to income generated).

Health insurance is becoming more popular, but most of these policies are employer-provided and cover only acute episodic illness. Many insurance plans pay the GP a very low rate; for example, $\$ 100$ (less than £7) per visit, including 2-3 days medication, which limits GP provision of episodic care only. Some health insurance plans require a hospital stay to qualify for reimbursement for procedures, including very simple procedures, such as wart removal, thus increasing costs. Many insurance policies do not cover psychological problems.

The third sector is mainly focused on providing social services, but some are also involved in direct medical services or allied health for care of the older population, which are not subsidised so these are also fee-charging. Third sector non-governmental organisations also run many health promotion programmes in 
the community, which are difficult to sustain.

Apart from western medicine, primary care is also provided by TCM practitioners, who are also perceived as competition by GPs. This pluralistic system has resulted in compartmentalised care in which patients may use public and private service alternatively or simultaneously, with increased risks of iatrogenic illness and wastage of resources. The main competition used to be clear cut between private GPs, TCM practitioners, and government clinics, but has recently become complicated by the emergence of large HMO-like groups, which pose a major threat to the financial viability of individual practitioners.

In addition, there is also an underlying competition between professional disciplines, which works against the development of the step-care approach and is certainly not good for managing chronic diseases. While there is no price differential for patients seeing doctors in the government sector when referred by private GPs, there is for the communitysupporting services such as community nurses, community allied health, and geriatric day hospitals. The result is an increasing dependency on the public sector for care of older people, which cannot meet the rising demands. In Hong Kong the dominance of GPs is very obvious, particularly in the private sector, and is another obstacle to the development of chronic disease management strategies and pathways.

\section{Steve Iliffe, Jean Woo, Cindy Lam, and Joyce T'ang}

DOI: 10.3399/bjgp10X483373

\section{Mike Fitzpatrick}

\section{The danger of doctors' advice}

A new report from the parliamentary Health Select Committee proposes drastic measures in an attempt to reduce the burden of alcohol-related illness and anti-social behaviour on the NHS and on British society more widely. ${ }^{1}$ A new crusade against alcohol is headed by a 'temperance triumvirate', Health Committee chair MP Kevin Barron, Chief Medical Officer (CMO) Sir Liam Donaldson, and Professor lan Gilmore, President of the Royal College of Physicians (RCP). The British Medical Association (BMA), the Royal College of General Practitioners, and the Faculty of Public Health all earnestly follow the lead of these Salvation Army revivalists, who sadly lack a brass band.

Critics have noted the socially regressive character of the new 'war on booze', with its focus on women, the poor, and young people, as well as its neglect of the personal and social benefits of alcohol, and its contribution to government revenues and employment. ${ }^{2}$

I was struck by one widely quoted sentence from the select committee report:

'It is time the Government listened more to the $\mathrm{CMO}$ and the President of the RCP and less to the drinks and retail industry." No doubt the type of partnership symbolised by the Bernie Ecclestone-Tony Blair relationship that led to the exemption of Formula One racing from regulations on tobacco sponsorship has also prevailed in alcohol policy. And it is true that the deregulation of licensing hours and the proliferation of cheap alcohol deals in supermarkets has encouraged late night city centre riotousness rather than promoting a 'civilised café culture' in Britain. But history suggests that doctors are no more reliable than brewers or publicans as guides to public policy.

Although the medical establishment now parades its devotion to the NHS, it fought fiercely against its introduction. Indeed the BMA continued to campaign against the NHS long after it had been established, although the RCP was more ambivalent, after Aneurin Bevan had notoriously 'stuffed their mouths with gold'. The medical profession, including both the BMA and the Royal College of
Obstetricians and Gynaecologists, was ambivalent about the Abortion Act when it was introduced by a private members bill in $1967 .^{3}$ Although both organisations are now vehemently hostile to the tobacco industry, the BMA and the RCP refused to take a public stand against smoking for a decade after its dangers were recognised. ${ }^{4}$

Taking a wider historical view, the medical profession has an even murkier record. In the early 20th century it was closely identified with the eugenics movement, endorsing compulsory sterilisation in the US and much worse in Nazi Germany. Doctors have ratified diverse forms of discrimination, from quotas for Jews in US medical schools to immigration restrictions on Commonwealth doctors in the UK. Doctors have played a prominent role in the medicalisation of women's lives, most notably in relation to the menopause (resulting in the substantial adverse consequences of long-term hormone replacement therapy). ${ }^{5}$ They have labelled homosexuality as a disease, and though having pathologised masturbation for decades, have lately embraced it as a form of 'safe sex'.

Now the government is urged to take advice on alcohol policy from a $\mathrm{CMO}$ whose prediction of 65000 deaths from swine flu exceeds by about 64000 the current total? Better to listen to the man or woman in the public bar, or at least their elected representatives.

\section{REFERENCES}

1. Parliament UK. The Health Committee. First Report of Session 2009-10 on Alcohol (HC 151-I) http://www.publications.parliament.uk/pa/cm2009 10/cmselect/cmhealth/151/15li.pdf (accessed 15 Jan 2010).

2. Reeves R. The worth of a pint. Guardian 2010; 7 January:

http://www.guardian.co.uk/commentisfree/2010/ja $\mathrm{n} / 07 /$ alcohol-drinking-temperance-society-culture (accessed 15 Jan 2010).

3. Rivett G. From cradle to grave: fifty years of the NHS London: Kings Fund. 1998.

4. Snowdon C. Velvet glove, iron fist: a history of antismoking. Ripon, Yorkshire: Little Dice, 2009.

5. Ehrenreich B. English D. For her own good: two centuries of experts advice to women. (revised edition). New York: Anchor, 2005.

DOI: 10.3399/bjgp10X483382 